\title{
Effects of mouthwashes on Knoop hardness and surface roughness of dental composites after different immersion times
}

Diogo de Azevedo Miranda ${ }^{(a)}$ Carlos Eduardo dos Santos Bertoldo(a)

Flávio Henrique Baggio Aguiar(a) Débora Alves Nunes Leite Lima ${ }^{(a)}$ José Roberto Lovadino(a)

(a) Department of Restorative Dentistry, Operative Dentistry Area, Piracicaba Dental School, State University of Campinas, Piracicaba, SP, Brazil.

\section{Corresponding Author:}

Flávio Henrique Baggio Aguiar

University of Campinas - UNICAMP

Piracicaba Dental School

Department of Restorative Dentistry

P.O. BOX 52

Avenida Limeira, 901, Areião

CEP: 13414-903

Piracicaba - SP- Brazil

E-mail: aguiar@fop.unicamp.br

Received for publication on Oct 28, 2010

Accepted for publication on Jan 03, 2011

\begin{abstract}
The aim of this in vitro study was to evaluate the effect of different mouthwashes on superficial roughness and Knoop hardness of two resin composites. Eighty specimens ( $6 \mathrm{~mm} \varnothing$ and $2 \mathrm{~mm}$ height) were prepared and divided into eight experimental groups $(\mathrm{n}=10)$ according to the resin composites (4 Seasons and Esthet X), and storage solutions (G1 - Distilled water; G2 - Colgate Plax Overnight; G3 - Colgate Plax Alcohol Free; and G4 - Colgate Plax Whitening). The initial hardness and roughness readings (T1) were measured and then the specimens were stored in $2 \mathrm{~mL}$ of mouthwash for $12 \mathrm{~h}$ (T2) and $24 \mathrm{~h}$ (T3). The data were analyzed with repeat-measures two-way ANOVA and Tukey's test $(\alpha=5 \%)$. Regardless of the type of solution and time of exposure, there was no statistical difference for roughness between the resins $(p=0.44)$. G4 and G8 presented higher roughness means than G1, G3, G5 and G7, after 12 and 24 hours of immersion. For Knoop microhardness analysis, there was a significant reduction for all groups after 12 hours and 24 hours. We conclude that the mouthwashes containing hydrogen peroxide and/or alcohol decrease the microhardness of the resins tested; however, the mouthwash containing hydrogen peroxide had a higher deleterious effect on roughness.
\end{abstract}

Descriptors: Composite Resins; Mouthwashes; Hardness; Surface Properties.

\section{Introduction}

Resin composites are made up of a polymeric matrix, filler particles, and silane-coupling agent that links the matrix to fillers. ${ }^{1,2}$ As a polymerbased material, the composites may undergo degradation inside the oral environment, resulting in alterations of the mechanical properties. ${ }^{3,4}$

The degradation is a complex mechanism dependent on the polymeric matrix, filler particles, and other processes, such as water uptake inside the matrix, ${ }^{5,6}$ thermal and mechanical cycling, and crack propagation and attenuation. ${ }^{7,8}$ In the clinical situation, composite degradation cannot be assigned to a single factor or chemical substance; rather, it is the result of complex reactions among different factors. ${ }^{9}$ Water is directly related to the composite organic matrix deterioration. The absorption of this liquid results in a widespread process within the composite resin ma- 
trix that causes its degradation and results in lower physical and mechanical properties, ${ }^{10,11}$ above all related to resin hardness and roughness. ${ }^{12}$

Mouthwashes are widely used to prevent and control caries and periodontal diseases, and are frequently used, even without professional prescription. The formulation of these mouthwashes consists of water, antimicrobial agents, salts, and, in some cases, alcohol, ${ }^{13}$ and the different concentrations of these substances can affect the $\mathrm{pH}$ of mouthwashes. However, the effects of such components on the composite resins polymeric matrix are widely discussed. ${ }^{14-16}$

In addition to conventional products containing alcohol, mouthwashes containing hydrogen peroxide have been marketed. However, in this case, besides hydrogen peroxide at low concentration, these mouthwashes contain alcohol in their composition. It is known that acid solutions may cause changes in the organic composition of resin composites. ${ }^{17}$ It is speculated that the high oxidative power of bleaching agents, in contact with organic molecules, could change the polymeric bonds and make the composite more susceptible to degradation. ${ }^{18}$ Furthermore, changes throughout the inorganic phase may decrease the material's physical properties, such as microhardness and roughness. ${ }^{17,18}$

Previous studies ${ }^{19-23}$ indicated that the literature is still controversial about the influence of mouthwashes on the mechanical and physical properties of composites, even in terms of their hardness and roughness. Thus, the aim of this in vitro study was to analyze the effects of mouthwashes with different compositions, after two immersion times, on the surface roughness and hardness of composites with different compositions of the organic matrix. The investigated null hypotheses were: (1) the composition of mouthwashes tested does not interfere with Knoop microhardness and surface roughness of resin composites; (2) the time of immersion in mouthwashes does not interfere with Knoop microhardness and surface roughness of resin composites tested; (3) the resin composites tested present no roughness and hardness differences.

\section{Materials and Methods}

Two resin composites were selected: 4 Seasons
(A3 - Ivoclar Vivadent, Schaan, Liechtenstein) and Esthet X (A3 - Dentsply, Milford, DE, USA). The composition of the resin composites is described in Table 1. Three mouthwashes were chosen: Plax Overnight $^{\circledR}$, Plax Alcohol free ${ }^{\circledR}$, Plax Whitening ${ }^{\circledR}$ (Colgate-Palmolive Ltda, São Bernardo do Campo, São Paulo, Brazil) and distilled water was used as control (Table 2), resulting in 8 groups $(\mathrm{n}=10)(\mathrm{Ta}-$ ble 3). To measure the $\mathrm{pH}, 20 \mathrm{ml}$ of each substance was added to a beaker, and the $\mathrm{pH}$ was obtained with a glass $\mathrm{pH}$ electrode $1.5 \mathrm{~cm}$ in diameter (PROCYON model AS 720 (Procyon Instrum. Científica Ltda, São Paulo, SP, Brazil) and each value is described in Table 2.

Cylindrical specimens were prepared in teflon ring molds $(6.0 \mathrm{~mm} \varnothing$ and $2 \mathrm{~mm}$ height). A polyester strip was placed on a glass slab (Dentsply, Petropólis, Rio de Janeiro, Brazil) and teflon matrix. After filling the mold to excess, the material surface was covered with another polyester strip and a glass slide, and compressed with a device $(500 \mathrm{~g})$ for $20 \mathrm{~s}$ to accommode the resin better and remove the excess material. All the resin composite specimens were light-activated with a quartz-tungsten-halogen unit Luting XL3000 (3M do Brasil, Sumaré, SP, Brazil) with $400 \mathrm{~mW} / \mathrm{cm}^{2}$ for 40 seconds, and stored in distilled water for $24 \mathrm{~h}$ at $37^{\circ} \mathrm{C}$. After this period, all specimens were finished with silicon carbide papers (Arotec, Cotia, SP, Brazil - 1200 grit) under constant water cooling.

Initially, the first reading (T1) of surface roughness was made with a profilometer roughness tester (Mitutoyo, Surftest 211; São Paulo, SP, Brazil) in

Table 1 - Composite resin, composition and batches.

\begin{tabular}{|c|c|c|}
\hline Resin & Batch & Composition \\
\hline Esthet X & 0708000242 & $\begin{array}{l}\text { UDMA, Bis-GMA, Bis-EMA, TEGDMA } \\
60 \text { vol\% of fluor-aluminum boron } \\
\text { barium silicate glass with particles } \\
\text { sized } 0.6-0.8 \mu \mathrm{m} \text { and silica } \\
\text { nanoparticles }(0.04 \mathrm{~nm})\end{array}$ \\
\hline $\begin{array}{c}4 \\
\text { Seasons }\end{array}$ & K27335 & $\begin{array}{l}\text { Bis-GMA, TEGDMA, UDMA } 76 \text { wt\% } \\
\text { of barium glass filler, trifluor terbium, } \\
\text { Ba-Al fluor silicate glass and dispersed } \\
\text { silica with filler particles sized } 0.04 \\
-3.0 \mu \mathrm{m} \text {, and filler average size of } \\
0.6 \mu \mathrm{m}\end{array}$ \\
\hline
\end{tabular}




\begin{tabular}{|c|c|c|c|c|}
\hline \multirow{4}{*}{$\begin{array}{r}\text { Table } 2 \text { - Mouthwashes, pH, } \\
\text { compositions and batches. }\end{array}$} & Solution & Batch & $\mathrm{pH}$ & Composition \\
\hline & $\begin{array}{l}\text { Colgate } \\
\text { Plax } \\
\text { Overnight }\end{array}$ & BR121A & 6.04 & $\begin{array}{l}\text { Water, glycerin, alcohol (8\%), propylene glycol, sorbitol, PEG-40 } \\
\text { hydrogenated castor oil, aroma, sodium benzoate, cetylpiridinium } \\
\text { chloride, sodium fluoride, sodium saccharin, Cl } 42090 \text {. }\end{array}$ \\
\hline & $\begin{array}{l}\text { Colgate } \\
\text { Plax } \\
\text { Alcohol } \\
\text { free }\end{array}$ & BR122A & 4.96 & $\begin{array}{l}\text { Water, glycerin, propylene glycol, sorbitol, PEG-40 hydrogenated } \\
\text { castor oil, aroma, phosphoric acid, sodium benzoate, cetylpiridinium } \\
\text { chloride, sodium fluoride, sodium saccharin, Cl } 42090\end{array}$ \\
\hline & $\begin{array}{l}\text { Colgate } \\
\text { Plax } \\
\text { Whitening }\end{array}$ & BR122A & 3.74 & $\begin{array}{l}\text { Water, sorbitol, ethylic alcohol (8\%), hydrogen peroxide (1.5\%), } \\
\text { polaxamere } 338 \text {, polissorbate } 20 \text {, methyl salicilate, menthol, sodium } \\
\text { saccharine, Cl } 42090\end{array}$ \\
\hline
\end{tabular}

three equidistant marks, and the surface hardness reading was made with a microdurometer (HMV, Shimadzu, Tokyo, Japan). Five consecutive and equidistant readings were obtained $(50 \mu \mathrm{m})$ per specimen to evaluate Knoop hardness (KHN), using a $50 \mathrm{~g}$ load, with a dwell time of $15 \mathrm{~s}$.

Each experimental group prepared was stored in $2 \mathrm{~mL}$ of the respective mouthwashes for $12 \mathrm{~h}$, which was reported to be equivalent to 1 year of daily mouthwash use, 2 min per day ${ }^{15}$. The samples in the mouthwashes were kept at $37^{\circ} \mathrm{C}$ throughout the study and were shaken on an orbital rotational table MA 140 CFT (Marconi Equipamentos, Piracicaba, SP, Brazil) every $3 \mathrm{~h}$, to provide homogeneity. After this period, the specimens were washed with abundant water and submitted to new roughness and hardness readings (T2). They were then re-immersed in solutions for a 12-hour period, totaling 24 hours of immersion. The specimens were then rinsed with abundant water and submitted to new roughness and hardness readings (T3) under the same experimental conditions. The control groups were tested in the same way as the experimental groups, after immersion in distilled water.

The obtained results for microhardness and roughness were tabulated, and the homogeneity was verified by Kolmogorov-Smirnov and Shapiro-Wilk tests. After observation of these parameters, a twoway Analysis of Variance with repeated-measures was performed. When the statistical significance was verified, the Tukey test was applied in order to compare results $(\alpha=5 \%)$. The statistical analysis was carried out with SAS 9.1 software (SAS Institute, Cary, NC, USA).
Table 3 - Group distribution, according to the composite resin and solution tested.

\begin{tabular}{c|l|c|l}
\hline \multicolumn{2}{c|}{ 4 Seasons } & \multicolumn{2}{c}{ Esthet X } \\
\hline G1 & Distilled water & G5 & Distilled water \\
\hline G2 & Plax Overnight $^{\circledR}$ & G6 & Plax Overnight ${ }^{\circledR}$ \\
\hline G3 & Plax Alcohol free $^{\circledR}$ & G7 & Plax Alcohol free \\
\hline G4 & Plax Whitening & \\
\hline
\end{tabular}

\section{Results \\ Knoop Microhardness}

The analysis of variance showed the interaction between the variables "composite resins", "immersion times" and "solutions" ( $\mathrm{p}=0.017)$. Means and standard deviations as well as results of Tukey test are presented in Table 4. There was a significant microhardness reduction for all groups after 12 hours (except for G5) and 24 hours. T3 differed from T2 for groups G2, G4, G6 and G8. G6 presented a higher hardness only for G2, in times T2 and T3, and G8 in time T3.

\section{Surface roughness}

The two-way Analysis of Variance ANOVA showed the interaction between the variables "immersion times" and "solutions" $(\mathrm{p}<0.001)$. There were no statistical differences between resins, regardless the type of solution and time $(\mathrm{p}=0.44)$. Table 5 presents means and standard deviation values for the factors type of mouthwash and time, and the results of Tukey's test. G4/G8 presented higher roughness means with statistical differences for G1, G3, G5 and G7, after 12 and 24 hours of immersion, and for G2 and G6 after 24 hours. G3 and G7 
Table 4 - Means Hardness (standard deviation) according of the type of resin, mouthwash and immersion time $(\mathrm{KNH})$.

\begin{tabular}{l|c|c|c|c}
\hline \multirow{3}{*}{ Composite } & \multirow{2}{*}{ Group } & \multicolumn{3}{|c}{ Time } \\
\cline { 2 - 5 } & $\mathrm{G} 1$ & $55.27(2.4) \mathrm{Aa}$ & $52.27(1.5) \mathrm{Ba}$ & $51.89(1.5) \mathrm{Ba}$ \\
\cline { 2 - 5 } & $\mathrm{G} 2$ & $53.19(2.2) \mathrm{Aa}$ & $40.88(1.8) \mathrm{Bc}$ & $32.97(1.5) \mathrm{Cc}$ \\
\cline { 2 - 5 } & $\mathrm{G} 3$ & $55.00(2.0) \mathrm{Aa}$ & $43.33(2.5) \mathrm{Bb}$ & $42.46(2.0) \mathrm{Bb}$ \\
\cline { 2 - 5 } & $\mathrm{G} 4$ & $55.30(2.4) \mathrm{Aa}$ & $38.76(2.0) \mathrm{Bd}$ & $31.88(1.9) \mathrm{Cc}$ \\
\hline \multirow{3}{*}{ Esthet X } & $\mathrm{G} 5$ & $54.91(2.6) \mathrm{Aa}$ & $52.65(2.0) \mathrm{Aba}$ & $50.49(2.5) \mathrm{Ba}$ \\
\cline { 2 - 5 } & $\mathrm{G} 6$ & $54.52(2.8) \mathrm{Aa}$ & $45.65(2.3) \mathrm{Bb} *$ & $35.14(1.2) \mathrm{Cc}$ \\
\cline { 2 - 5 } & $\mathrm{G} 7$ & $55.16(2.3) \mathrm{Aa}$ & $44.96(3.3) \mathrm{Bb}$ & $42.66(2.8) \mathrm{Bb}$ \\
\cline { 2 - 5 } & $\mathrm{G} 8$ & $54.69(2.8) \mathrm{Aa}$ & $38.37(1.9) \mathrm{Bc}$ & $35.73(2.0) \mathrm{Cc}$ \\
\hline
\end{tabular}

Means followed by different letters (capital letters in the horizontal and lower case letters in the vertical) differ between them in the Tukey's test $(p<0.05) .{ }^{*}$ Significant difference between the two tested resins.

statistically differed from G1 and G5 after 24 hours. As far as groups G2, G3, G4, G6, G7 and G8 are concerned, there were differences between immersion times in that T3 differed from T1. T3 differed from T2 only for G2, G4, G6 and G8.

\section{Discussion}

According to the results of this study, the first null hypothesis that the different mouthwashes do not interfere with the Knoop hardness and surface roughness of composites was rejected. Furthermore, the roughness values increased according to the immersion time. Unlike the roughness results, the microhardness values decreased with immersion in the mouthwashes. The second null hypothesis of the present study was therefore rejected.

The chemical composition of resin composites may interfere in the susceptibility to softening and degradation. ${ }^{24,25}$ The resin 4 Seasons presented more alteration in hardness after immersion in mouthwashes tested, compared to Esthet-X. The first resin contains Bis-GMA and UDMA in its composition, and it is known that these monomers are more susceptible to softening after exposure to chemical agents. ${ }^{19}$ However, the composite Esthet-X contains Bis-EMA, and reduced amount of TEGDMA, and these characteristics promote better resistance of the composite resin to the action of chemical substance. $^{26}$

The third null hypothesis that the roughness and hardness of the resins tested would be similar was partially accepted, since the resins present different
Table 5 - Roughness means (standard deviation) according to immersion time in different mouthwash solutions (Ra).

\begin{tabular}{l|c|c|c}
\hline \multirow{2}{*}{ Groups } & \multicolumn{3}{|c}{ Time } \\
\cline { 2 - 4 } & $\mathrm{T} 1$ & $\mathrm{~T} 2$ & $\mathrm{~T}$ \\
\hline G1/G5 & $0.29(0.03) \mathrm{Aa}$ & $0.31(0.02) \mathrm{Ac}$ & $0.31(0.03) \mathrm{Ad}$ \\
\hline G2/G6 & $0.31(0.04) \mathrm{Ca}$ & $0.34(0.02) \mathrm{Bab}$ & $0.37(0.04) \mathrm{Ab}$ \\
\hline G3/G7 & $0.30(0.03) \mathrm{Ba}$ & $0.32(0.02) \mathrm{Abc}$ & $0.33(0.04) \mathrm{Ac}$ \\
\hline G4/G8 & $0.31(0.04) \mathrm{Ca}$ & $0.37(0.05) \mathrm{Ba}$ & $0.41(0.02) \mathrm{Aa}$ \\
\hline
\end{tabular}

Means followed by different letters (capital letters in the horizontal and lower case letters in the vertical) differ between them in the Tukey's test $(p<0.05)$.

microhardness but similar roughness. The presence of Bis-EMA incorporated in the organic matrix of Esthet $\mathrm{X}$ and distribution, type and size of filler particles $^{27,28}$ probably resulted in higher hardness values compared to the composite 4 Seasons. For roughness, no differences were observed between the resins, which suggest that the increased roughness is directly related to the composition, $\mathrm{pH}$ and immersion time in solution. ${ }^{11}$

Furthermore, the $\mathrm{pH}$ of the tested solutions provides another possible preponderant factor for the composite matrix degradation. Analyzing the composition of mouthwashes in Table 2, we observe that Plax Alcohol Free contains phosphoric acid and Plax Whitening contains hydrogen peroxide. The measurement of $\mathrm{pH}$ of these mouthwashes was 4.96 and 3.74, respectively. Compared to distilled water $(\mathrm{pH}=5.5)$ the higher acidity may have altered the polymeric matrixes of the resin composite by catalysis of ester groups from dimethacrylate monomers 
present in their compositions (Bis-GMA, Bis-EMA, UDMA or TEGDMA). The hydrolysis of these ester groups may have formed alcohol and carboxylic acid molecules, which accelerate the degradation of the resin composites, due to the decrease of $\mathrm{pH}$ inside the resin matrix. ${ }^{25}$

Another study ${ }^{29}$ showed that the low $\mathrm{pH}$ of solutions may induce phenomena of sorption and hygroscopic expansion, due to the production of methacrylic acid, the result of the degradation process of the enzymatic hydrolysis.

Using the solubility parameters of polymers in alcohol solvents, the higher softening of resin composites occurred with $75 \%$ ethanol, when compared to those of $100 \%, 50 \%, 25 \%$, or $0 \%$ ethanol. However, the effect of the chemical agent on the hardness of the composite resin is material-dependent. ${ }^{23}$ Another study has also reported that beverages containing $9 \%$ or more of ethanol might lead to softening of the restorative material matrix, interfering in the polymer-filler particle interface, increasing the wear. ${ }^{30}$ However, considering that the specimens were immersed in solutions with up to $8 \%$ alcohol concentration, the solubility of the material resulted in detachment of filler particles ${ }^{25}$ and probably caused

\section{References}

1. Yap AU, Chew CL, Ong LF, Teoh SH. Environmental damage and occlusal contact area wear of composite restoratives. J Oral Rehabil. 2002 Jan;29(1):87-97.

2. Mitra SB, Wu D, Holmes BN. An application of nanotechnology in advanced dental materials. J Am Dent Assoc. 2003 Oct;134(10):1382-90.

3. Ferracane JL. Hygroscopic and hydrolytic effects in dental polymer networks. Dent Mater. 2006 Mar;22(3):211-22.

4. Curtis AR, Shortall AC, Marquis PM, Palin WM. Water uptake and strength characteristics of a nanofilled resin-based composite. J Dent. 2008 Mar;36(3):186-93.

5. Gonçalves L, Filho JD, Guimarães JG, Poskus LT, Silva EM. Solubility, salivary sorption and degree of conversion of dimethacrylate-based polymeric matrixes. J Biomed Mater Res B Appl Biomater.2008 May;85(2):320-5.

6. da Silva EM, Almeida GS, Poskus LT, Guimarães JG. Relationship between the degree of conversion, solubility and salivary sorption of a hybrid and a nanofilled resin composite: Influence of the light-activation mode. J Appl Oral Sci. 2008 Apr;16(2):161-6. degradation of the material surface, resulting in a decrease of hardness and an increase of roughness.

Clinically, the mouthwashes' effects on resin composites may be different according to some factors, such as acquired biofilm, food habits, beverages, and oral care products, which cannot be reproduced in vitro. Those factors, acting together or in isolation, may interfere with the physical and mechanical properties of the materials, influencing the durability of the restorative treatment.

\section{Conclusions}

In conclusion, the results of this study showed that those mouthwashes containing alcohol or hydrogen peroxide present a higher potential to change the superficial roughness and hardness of the tested composites. The length of immersion time affected the Knoop microhardness and surface roughness of the composites tested, above all among mouthwashes containing alcohol or hydrogen peroxide, and alcohol-free mouthwashes affected the hardness and roughness of composites more than distilled water. Composite resins presented differences only in hardness properties after immersion in mouthwashes containing alcohol or hydrogen peroxide.

7. Beun S, Glorieux T, Devaux J, Vreven J, Leloup G. Characterization of nanofilled compared to universal and microfilled composites. Dent Mater. 2007 Jan;23(1):51-9.

8. Rodrigues Junior SA, Zanchi CH, Carvalho RV, Demarco FF. Flexural strength and modulus of elasticity of different types of resin-based composites. Braz Oral Res. 2007 JanMar;21(1):16-21.

9. Sarret DC, Söderholm JM, Batich CD. Water and abrasive effects on three-body wear of composites. J Dent Res. 1991 Jul;70(7):1074-81.

10. Okada K, Tosaki S, Hirota K, Hume WR. Surface hardness change of restorative filling materials stored in saliva. Dent Mater. 2001 Jan;17(1):34-9.

11. Gürdal P, Güniz Akdeniz B, Hakan Sen B. The effects of mouthrinses on microhardness and colour stability of aesthetic restorative materials. J Oral Rehabil. 2002 Sep;29(9):895-901.

12. Ortengren U, Andersson F, Elgh U, Terselius B, Karlsson S. Influence of $\mathrm{pH}$ and storage time on the sorption and solubility behaviour of three composite resin materials. J Dent. 2001 Jan;29(1):35-41 
13. Moran JM. Chemical plaque control-prevention for the masses. Periodonto. 2000 Oct;15:109-17.

14. Almeida GS, Poskus LT, Guimarães JG, da Silva EM. The effect of mouthrinses on salivary sorption, solubility and surface degradation of a nanofilled and a hybrid resin composite. Oper Dent. 2010 Jan-Feb;35(1):105-11.

15. Gürgan S, Önen A, Köprülü H. In vitro effects of alcoholcontaining and alcohol-free mouthrinses on microhardness of some restorative materials. J Oral Rehabil. 1997 Mar;24(3):244-6.

16. Cavalcanti AN, Mitsui FH, Ambrosano GM, Mathias P, Marchi GM. Effect of different mouthrinses on Knoop hardness of a restorative composite. Am J Dent. 2005 Dec;18(6):338-40.

17. Lima DA, De Alexandre RS, Martins AC, Aguiar FH, Ambrosano GM, Lovadino JR. Effect of curing light and bleching agents on physical properties of a hybrid composite resin. J Esthet Restor Dent. 2008 Aug;20(4):266-75.

18. de Alexandre RS, Sundfeld RH, Briso AL, Bedran-Russo AK, Valentino TA, Sundefeld ML. Effect of $10 \%$ carbamide peroxide dental bleaching on microhardness of filled and unfilled sealant materials. J Esthet Restor Dent. 2006 SepOct;18(5):273-8.

19. Langsten RE, Dunn WJ, Hartup GR, Murchison DF. Higherconcentration carbamide peroxide effects on surface roughness of composites. J Esthet Restor Dent. 2002 Mar;14(2):926.

20. Garcia-Godoy F, Garcia-Godoy A. Effect of bleaching gels on the surface roughness, hardness, and micromophology of composites. Gen Dent. 2002 May-Jun;50(3):247-50.

21. Türkun M, Sevgican F, Pehlivan Y, Aktener BO. Effects of $10 \%$ carbamide peroxide on the enamel surface morphology: a scanning electrón microscopy study. J Esthet Restor Dent. 2002 Jul;14(4):238-44.

22. Bailey S, Swift Junior E. Effects of home bleaching products on composite resins. Quintessence Int. 1992 Jul;23(7):489-94.

23. Yap AU, Tan SH, Wee SS, Lee CW, Lim EL, Zeng KY. Chemical degradation of composite restorative. J Oral Rehabil. 2001 Nov;28(11):1015-21.

24. Ferracane JL, Berge HX. Fracture toughness of experimental dental composites aged in ethanol. J Dent Res. 1995 Jul;74(7):1418-23.

25. Almeida GS, Poskus LT, Guimarães JG, da Silva EM. The effect of mouthrinses on salivary sorption, solubility and surface degradation of a nanofilled and a hybrid resin composite. Oper Dent. 2010 Jan-Feb;35(1):105-111.

26. Moraes RR, Sinhoreti MA, Correr-Sobrinho L, Ogliari FA, Piva E, Petzhold CL. Preparation and evaluation of dental resin luting agents with increasing content of bisphenol-A ethoxylated dimethacrylate. J Biomater Appl. 2010 Jan;24(5):453-73.

27. Karabela MM, Sideridou ID. Effect of the structure of silane coupling agent on sorption characteristics of solvents by dental resin-nanocomposites. Dent Mater. 2008 Dec; 24(12):1631-9.

28. Zhang Y, Xu J. Effect of immersion in various media on the sorption, solubility, elution of unreacted monomers, and flexural properties of two model dental composite compositions. J Mater Sci Mater Med. 2008 Jun;19(6):2477-83.

29. Örtengren U, Andersson F, Elgh U, Terselius B, Karlsson S. Influence of $\mathrm{pH}$ and storage time on the sorption and solubility behaviour of three composite resin materials. J Dent. 2001 Jan;29(1):35-41.

30. Sarret DC, Coletti DP, Peluso AR. The effects of alcoholic beverages on composite wear. Dent Mater.2000 Jan;16(1):62-7. 